\title{
RHODANINE COMPLEXES OF COPPER(I), PALLADIUM(II) AND PLATINUM(II)
}

\author{
F. G. MOERS, J. W. M. GOOSSENS and J. P. M. LANGHOUT \\ Department of Inorganic Chemistry, University of Nijmegen, Toernooiveld, Nijmegen, \\ The Netherlands
}

(Received 7 March 1972)

\begin{abstract}
The preparation of copper(I), palladium(II) or platinum(II) complexes with 5-methylrhodanine, 3-allylrhodanine, 3,3'-ethylenebisrhodanine and 3,3'-butylenebisrhodanine are described. The coordination in the complexes takes place through the thiocarbonyl group of the ligand. Copper forms $1: 1,1: 2$ and $3: 4$ complexes with 5-methylrhodanine. The i.r. spectrum of the complex $\mathrm{Cu}(3-$ allylrhodanine) $\mathrm{Cl}$ suggests that copper is bonded via the thiocarbonyl group and the olefinic double bond of the ligand. The ligands 3,3'-ethylenebisrhodanine and 3,3'-butylenebisrhodanine form 1:1 complexes with copper and palladium.
\end{abstract}

\section{INTRODUCTION}

COORDINATION complexes of rhodanine and its 3-substituted derivatives as ligand have been studied with copper(I), silver(I), palladium(II) and platinum(II). From i.r. spectra and NMR measurements it was concluded that the coordination in these complexes takes place through the thiocarbonyl group of the ligand $[1,2]$. The X-ray structure of 3-methylrhodanine copper $(L)$ iodide indicates a polymeric structure in which the iodine atoms act as bridges and the ligand 3-methylrhodanine is terminal coordinated with the thiocarbonyl group of the ligand [3].

This study describes complexes with the 5-substituted rhodanine 5-methyl $\mathrm{CH}_{3}$

rhodanine $\mathrm{HN}-\mathrm{CO}-\mathrm{CH}-\mathrm{S}-\mathrm{CS}$, abbreviated at 5-MeRd, and some 3-substituted rhodanines $\mathrm{RN}-\mathrm{CO}-\mathrm{CH}_{2}-\mathrm{S}-\mathrm{CS}: \quad 3$-allylrhodanine: $\quad R=\mathrm{CH}_{2}-\mathrm{CH}=\mathrm{CH}_{2}$, abbreviated as AllRd. 3,3'-ethylenebisrhodanine: $R=\left(\mathrm{CH}_{2}\right)_{2}-\mathrm{N}-\mathrm{CO}-\mathrm{CH}_{2}-\mathrm{S}-\mathrm{CS}$, abbreviated as EnRd. 3,3'-butylenebisrhodanine: $R=\left(\mathrm{CH}_{2}\right)_{4}-\mathrm{N}-\mathrm{CO}-\mathrm{CH}_{2}-\mathrm{S}-\mathrm{CS}$, abbreviated as BunRd. These 3-substituted rhodanines may act as bidentate ligands.

\section{Preparation of the ligands}

\section{EXPERIMENTAL}

5-Methylrhodanine was prepared from $\alpha$-bromopropionic acid and ammonium dithiocarbamate as described by Holmberg[4] (m.p. $78^{\circ} \mathrm{C}$ ).

3-Allylrhodanine was prepared from thioglycollic acid and allylisothiocyanate according to Andreasch and Zipser [5] (m.p. $42^{\circ} \mathrm{C}$ ).

3,3'-Ethylenebisrhodanine and 3,3'-butylenebisrhodanine were prepared from ethylenediamine

1. F. G. Moers and J. J. Steggerda, J. inorg. nucl. Chem. 30, 3217 (1968).

2. F. G. Moers and J. P. Langhout, Rec. Trav. Chim. 89, 1237 (1970).

3. F. G. Moers, W. P. J. H. Bosman and P. T. Beurskens, J. cryst. molec. Struct. 2,23 (1972).

4. B. Holmberg, J. prakt. Chem. 81 (2), 451 (1910).

5. R. Andreasch and A. Zipser, Mh. Chem. 24, 504 (1903). 
$1 \cdot 2$ or butylenediamine 1.4 , carbon disulphide and sodium chloroacetate as described by Dabrowska et al. [6] (m.p. $196^{\circ}$ and $132^{\circ} \mathrm{C}$, respectively).

\section{Other chemicals}

All chemicals and solvents were of reagent grade.

Preparation of the complexes with 5-methylrhodanine. A solution of 5-methylrhodanine in ethanol was added with stirring at room temperature to a solution of $\mathrm{Cu} X$ in aqueous $2 \mathrm{~N} \mathrm{H} X$ with $X=\mathrm{Cl}, \mathrm{Br}$ or $I$ in a nitrogen atmosphere. The copper ligand mole ratio was $1: 2$. The precipitate was filtered, washed with water and ethanol and dried in vacuum over $\mathrm{P}_{2} \mathrm{O}_{5}$.

Preparation of the complexes with 3-allylrhodanine. A solution of $0.4 \mathrm{~m}$-mole $\mathrm{K}_{2} M \mathrm{Cl}_{4}$ with $M=$ $\mathrm{Pd}$ or $\mathrm{Pt}$ in aqueous $0.5 \mathrm{~N} \mathrm{HCl}$ was added with stirring at room temperature to a solution of $1 \mathrm{~m}$-mole 3-allylrhodanine in propanol-2 in a nitrogen atmosphere. The precipitate was filtered, washed with water and propanol-2 and dried in vacuum over $\mathrm{P}_{2} \mathrm{O}_{5}$. The copper complex was prepared in a similar way, with however a copper ligand ratio 1:1 and ethanol was used instead of propanol-2.

Preparation of the complexes with 3,3'-ethylenebisrhodanine or 3,3'-butylenebisrhodanine. A saturated solution of $\mathrm{CuCl}$ or $\mathrm{K}_{2} \mathrm{PdCl}_{4}$ in $1 \mathrm{~N} \mathrm{HCl}$ was added with stirring at room temperature to a solution of the ligand in ethanol in a nitrogen atmosphere. The ligand mole ratio was $1: 1$. The precipitate was filtered, washed with water and ethanol and dried in vacuum over $\mathrm{P}_{2} \mathrm{O}_{5}$.

The analyses of the compounds are given in Table 1.

Table 1. Chemical analysis of the complexes

\begin{tabular}{|c|c|c|c|c|c|c|}
\hline Complex & $\begin{array}{l}\text { Metal } \\
(\%)\end{array}$ & $\begin{array}{c}\text { Halogen } \\
\text { (\%) }\end{array}$ & $\begin{array}{c}\text { Carbon } \\
(\%)\end{array}$ & $\begin{array}{c}\text { Hydrogen } \\
\text { (\%) }\end{array}$ & $\begin{array}{l}\text { Sulphur } \\
(\%)\end{array}$ & $\begin{array}{c}\text { Nitroger } \\
(\%)\end{array}$ \\
\hline $\mathrm{Cu}_{3}(5-\mathrm{MeRd})_{4} \mathrm{Cl}_{3}$ & $\begin{array}{c}20.85 \\
(21.52)\end{array}$ & $\begin{array}{c}11 \cdot 69 \\
(12 \cdot 01)\end{array}$ & $\begin{array}{c}22 \cdot 21 \\
(21 \cdot 69)\end{array}$ & $\begin{array}{c}2 \cdot 15 \\
(2 \cdot 29)\end{array}$ & & $\begin{array}{c}6 \cdot 37 \\
(6 \cdot 32)\end{array}$ \\
\hline $\mathrm{Cu}(5-\mathrm{MeRd}) \mathrm{Br}$ & $\begin{array}{c}14 \cdot 24 \\
(14 \cdot 51)\end{array}$ & $\begin{array}{c}17 \cdot 94 \\
(18 \cdot 25)\end{array}$ & $\begin{array}{c}21.67 \\
(21.95)\end{array}$ & $\begin{array}{c}2 \cdot 52 \\
(2 \cdot 30)\end{array}$ & & $\begin{array}{c}5.94 \\
(6.39)\end{array}$ \\
\hline $\mathrm{Cu}(5-\mathrm{MeRd}) \mathrm{I}$ & $\begin{array}{c}18 \cdot 57 \\
(18 \cdot 81)\end{array}$ & $\begin{array}{c}37 \cdot 33 \\
(37 \cdot 59)\end{array}$ & $\begin{array}{c}14 \cdot 25 \\
(14 \cdot 23)\end{array}$ & $\begin{array}{c}1.41 \\
(1.49)\end{array}$ & & $\begin{array}{c}4 \cdot 33 \\
(4 \cdot 15)\end{array}$ \\
\hline $\mathrm{Cu}(\mathrm{AllRd}) \mathrm{Cl}$ & $\begin{array}{c}23.08 \\
(23.34)\end{array}$ & $\begin{array}{c}12.92 \\
(13.02)\end{array}$ & $\begin{array}{c}26 \cdot 62 \\
(26 \cdot 47)\end{array}$ & $\begin{array}{c}2.54 \\
(2.59)\end{array}$ & & $\begin{array}{c}5-09 \\
(5 \cdot 14)\end{array}$ \\
\hline $\operatorname{Pd}(\text { AllRd })_{2} \mathrm{Cl}_{2}$ & $\begin{array}{c}20 \cdot 82 \\
(20 \cdot 33)\end{array}$ & & $\begin{array}{c}26.85 \\
(27.52)\end{array}$ & $\begin{array}{c}2.59 \\
(2.69)\end{array}$ & & $\begin{array}{c}5 \cdot 22 \\
(5 \cdot 35)\end{array}$ \\
\hline $\operatorname{Pt}(\mathrm{AllRd})_{2} \mathrm{Cl}_{2}$ & $\begin{array}{c}31 \cdot 38 \\
(31 \cdot 87)\end{array}$ & & $\begin{array}{c}23 \cdot 13 \\
(23 \cdot 53)\end{array}$ & $\begin{array}{c}2 \cdot 35 \\
(2 \cdot 30)\end{array}$ & $\begin{array}{c}20 \cdot 21 \\
(20 \cdot 94)\end{array}$ & $\begin{array}{c}4 \cdot 21 \\
(4 \cdot 57)\end{array}$ \\
\hline $\mathrm{Cu}(\mathrm{EnRd}) \mathrm{Cl}$ & $\begin{array}{c}15.91 \\
(16 \cdot 23)\end{array}$ & & $\begin{array}{c}25 \cdot 12 \\
(24 \cdot 55)\end{array}$ & $\begin{array}{c}2 \cdot 17 \\
(2 \cdot 06)\end{array}$ & & $\begin{array}{c}7 \cdot 20 \\
(7 \cdot 16)\end{array}$ \\
\hline $\operatorname{Pd}(\mathrm{EnRd}) \mathrm{Cl}_{\mathbf{2}}$ & & $\begin{array}{c}15.05 \\
(15 \cdot 10)\end{array}$ & $\begin{array}{c}20 \cdot 28 \\
(20 \cdot 46)\end{array}$ & $\begin{array}{c}1.80 \\
(1.72)\end{array}$ & & $\begin{array}{c}5 \cdot 64 \\
(5 \cdot 96)\end{array}$ \\
\hline $\mathrm{Pd}(\mathrm{BunRd}) \mathrm{Cl}_{2}$ & $\begin{array}{c}22 \cdot 07 \\
(21 \cdot 37)\end{array}$ & & $\begin{array}{c}23 \cdot 07 \\
(24 \cdot 13)\end{array}$ & $\begin{array}{c}2 \cdot 34 \\
(2 \cdot 43)\end{array}$ & & $\begin{array}{c}5 \cdot 59 \\
(5 \cdot 63)\end{array}$ \\
\hline
\end{tabular}

Theoretical values are given in parentheses.

\section{Physical measurements}

Magnetic susceptibilities were measured on a Gouy balance. The i.r. spectra were obtained with a Perkin-Elmer 257 spectrophotometer for the range $4000-700 \mathrm{~cm}^{-1}$ and a Hitachi EPI-L for the 700$200 \mathrm{~cm}^{-1}$ region. The spectra were taken using the $\mathrm{KBr}$ or CsI disc technique and checked with Nujol mulls. An i.r. spectrum of $\mathrm{Cu}$ (3-allylrhodanine) $\mathrm{Cl}$ was also taken in dimethylsulphoxide (DMSO). The preparation of the DMSO solution was performed in a Vac train HE 193-1 glove box under a nitrogen atmosphere. NMR spectra were determined with a Varian T-60 spectrometer. For NMR

6. M. Dabrowska-Przybylska, J. Swiderski and W. Markocki, Rocz. Chem. 43, 1499 (1969); Chem. Abstr. 72, 4320p (1970). 
study the samples were prepared by dissolving them in deuterated dimethyl dulphoxide (99.9 per cent purity, obtained from Merck, Sharp and Dohme), hexamethyldisiloxan being used as external standard.

\section{RESULTS AND DISCUSSION}

The compounds described in this work are listed in Table 1. The compounds are diamagnetic, as would be expected for copper(I) compounds and for planar coordination around $\mathrm{Pd}(\mathrm{II})$ and $\mathrm{Pt}(\mathrm{II})$ in these complexes. The most important infrared absorption bands are shown in Table 2 and NMR data are reported in Table 3.

Table 2. Infrared data in the range $4000-200 \mathrm{~cm}^{-1}$

\begin{tabular}{|c|c|c|c|c|}
\hline \multirow[b]{2}{*}{ Compounds } & \multicolumn{2}{|c|}{$\nu \mathrm{C}=\mathrm{S}$} & \multirow{2}{*}{$\begin{array}{c}\nu \mathrm{N}-\mathrm{H} \text { or } \\
\nu C=\mathrm{C}\end{array}$} & \multirow{2}{*}{$\begin{array}{c}\nu M-X \text { or } \\
\nu M-\mathrm{S}\end{array}$} \\
\hline & First band & Second band & & \\
\hline 5-MeRd & $1075(\mathrm{~s})$ & $1228(s)$ & 3090 & \\
\hline $\mathrm{Cu}_{3}(5-\mathrm{MeRd})_{4} \mathrm{Cl}_{3}$ & $1065(\mathrm{~m})$ & $1220(\mathrm{~m})$ & $3070^{b}$ & $300(\mathrm{~m})$ \\
\hline $\mathrm{Cu}(5-\mathrm{MeRd})_{2} \mathrm{Br}$ & $1069(\mathrm{~s})$ & $1220(s)$ & 3100 & $302^{b}(\mathrm{~m})$ \\
\hline $\mathrm{Cu}(5-\mathrm{MeRd}) \mathrm{I}$ & $1081(\mathrm{~s})$ & $1230(\mathrm{~s})$ & 3090 & $300(\mathrm{~s})$ \\
\hline AllRd & $1100^{b}(\mathrm{~m})$ & $1191^{b}(\mathrm{~s})$ & $1643(\mathrm{~m})$ & \\
\hline $\mathrm{Cu}(\mathrm{AllRd}(\mathrm{Cl}$ & $1088(m)$ & $1183(s)$ & $1538(\mathrm{~m})$ & $285^{b}(s)$ \\
\hline $\mathrm{Pd}(\mathrm{AllRd})_{2} \mathrm{Cl}_{2}$ & $1068(w)$ & $1180(s)$ & $1640(\mathrm{~m})$ & $\begin{array}{l}370(w), 337(s) \\
320(s), 303(s)\end{array}$ \\
\hline $\operatorname{Pt}(\text { AllRd })_{2} \mathrm{Cl}_{2}$ & $1065(w)$ & $1187^{b}(s)$ & $1640(\mathrm{~m})$ & $\begin{array}{l}376(w), 327(s) \\
315(s)\end{array}$ \\
\hline EnRd & $1110(\mathrm{~m})$ & $\begin{array}{l}1220(\mathrm{~s}) \\
1210(\mathrm{~s})\end{array}$ & & \\
\hline $\mathrm{Cu}(\mathrm{EnRd}) \mathrm{Cl}$ & $1110(\mathrm{vw})$ & $\begin{array}{l}1220(\mathrm{~s}) \\
1209(\mathrm{~m})\end{array}$ & & $326(\mathrm{~m}), 310(\mathrm{~m})$ \\
\hline $\mathbf{P d}(\mathrm{EnRd}) \mathrm{Cl}_{2}$ & $1105(\mathrm{vw})$ & $1210^{b}(\mathrm{~m})$ & & $338^{b}(\mathrm{~s}), 310(\mathrm{~m})$ \\
\hline BunRd & $1120(\mathrm{~m})$ & $\begin{array}{l}1226(\mathrm{~s}) \\
1216(\mathrm{~s})\end{array}$ & & \\
\hline $\mathrm{Pd}(\mathrm{BunRd}) \mathrm{Cl}_{2}$ & 1094(m) & $1218(s)$ & & $\begin{array}{l}337(\mathrm{~s}), 317^{\mathrm{sh}}(\mathrm{m}) \\
308(\mathrm{~s})\end{array}$ \\
\hline
\end{tabular}

\section{(a) Complexes of 5-methylrhodanine}

The interaction of the copper halides in acid medium with the ligand 5-methylrhodanine results in copper complexes with the formulae $\mathrm{Cu}(5-\mathrm{MeRd}) \mathrm{I}, \mathrm{Cu}(5-$ $\mathrm{MeRd})_{2} \mathrm{Br}$ and $\mathrm{Cu}_{3}(5-\mathrm{MeRd})_{4} \mathrm{Cl}_{3}$. The products are insoluble in the usual organic solvents. The $\mathrm{Cu}-\mathrm{S}$ stretching vibration has been observed at about $300 \mathrm{~cm}^{-1}$. In the products $\mathrm{Cu}_{3}(5-\mathrm{MeRd})_{4} \mathrm{Cl}_{3}$ and $\mathrm{Cu}(5-\mathrm{MeRd})_{2} \mathrm{Br}$ we found a lowering in frequency for two bands involving the $\mathrm{C}=\mathrm{S}$ stretching vibration, indicating ligation through the thiocarbonyl group of the ligand. In the complex $\mathrm{Cu}(5-\mathrm{MeRd}) \mathrm{I}$ there is also little doubt that coordination is through the thiocarbonyl group (as can be concluded from the observation of a M-S stretching vibration). However it is surprising that the $\mathrm{C}=\mathrm{S}$ stretching vibrations do not decrease in this complex. A lengthening of the $\mathrm{C}=\mathrm{S}$ distance of $0.1 \AA$ was found in the complex $\mathrm{Cu}$ (thiourea $)_{3} \mathrm{Cl}$ [7]. However in the complexes $\mathrm{Cu}$ (thiourea) $)_{2} \mathrm{Cl}[8]$ and $\mathrm{Cu}_{4}$ (thiourea) ${ }_{9}$ -

7. C. B. Knobler, Y. Okaya and R. Pepinsky, Z. Kristallogr. 111, 385 (1959).

8. W. A. Spofford and E. L. Amma, Chem. Comm. 7, 405 (1968). 
Table 3. Nuclear magnetic resonance data

\begin{tabular}{|c|c|c|c|c|c|c|c|}
\hline Compounds & $\begin{array}{c}\delta_{\mathrm{CH}} \\
(\mathrm{ppm})\end{array}$ & $\begin{array}{r}\delta_{\mathrm{CH}_{3}} \\
(\mathrm{ppm})\end{array}$ & $\begin{array}{c}\delta_{\mathrm{NH}} \\
(\mathrm{ppm})\end{array}$ & $\begin{array}{c}\delta_{\mathrm{CHarlng}}+\delta_{\mathrm{N}-\mathrm{CHz}} \\
(\mathrm{ppm})\end{array}$ & $\begin{array}{c}\delta_{\mathrm{CH}} \\
(\mathrm{ppm})\end{array}$ & $\begin{array}{c}\delta_{\mathrm{CHs}} \\
(\mathrm{ppm})\end{array}$ & $\begin{array}{c}\text { DMSO-d }^{5} \\
(\mathrm{ppm})\end{array}$ \\
\hline 5-MeRd & $4 \cdot 7-4 \cdot 9$ & $1.7-1.8$ & $13 \cdot 0-13 \cdot 4$ & & & & $2 \cdot 76$ \\
\hline $\mathrm{Cu}(5-\mathrm{MeRd}) \mathrm{I}$ & $4 \cdot 7-4 \cdot 9$ & $1 \cdot 7-1.8$ & $12 \cdot 8-13 \cdot 2$ & & & & $2 \cdot 69$ \\
\hline $\mathrm{Cu}(5-\mathrm{MeRd})_{2} \mathrm{Br}$ & $4 \cdot 5-4 \cdot 8$ & $1.5-1.6$ & $12 \cdot 8-13-2$ & & & & $2 \cdot 62$ \\
\hline AllRd & & & & $4-3-4 \cdot 7$ & $5 \cdot 6-6 \cdot 1$ & $5 \cdot 1-5 \cdot 4$ & $2 \cdot 58$ \\
\hline $\mathrm{Cu}$ (AllRd)Cl & & & & $4 \cdot 3-4 \cdot 7$ & $5-5-6-0$ & $5 \cdot 1-5 \cdot 4$ & 2.64 \\
\hline $\mathrm{Pd}(\mathrm{AllRd})_{2} \mathrm{Cl}$ & & & & $4 \cdot 4-4-8$ & $5 \cdot 7-6 \cdot 1$ & $5 \cdot 2-5 \cdot 5$ & $2 \cdot 70$ \\
\hline $\mathrm{Pt}(\mathrm{AllRd})_{2} \mathrm{Cl}_{2}$ & & & & $4 \cdot 3-4 \cdot 7$ & $5 \cdot 6-6 \cdot 1$ & $5 \cdot 1-5 \cdot 4$ & $2 \cdot 59$ \\
\hline
\end{tabular}

$\left(\mathrm{NO}_{3}\right)_{4}[9]$ in which short copper-copper distances (2.98 and $2 \cdot 71 \AA$, respectively) are present, a lengthening of the $\mathrm{C}=\mathrm{S}$ distance was not observed. In the complex $\mathrm{Cu}(3-\mathrm{MeRd}) \mathrm{I}$ [3] with copper-copper distances 2.96 and 3.01 $\AA$ the $\mathrm{C}=\mathrm{S}$ distance is only slightly greater than in the compound rhodanine. It seems that in these compounds with short copper-copper distances a lengthening of the $\mathrm{C}=\mathrm{S}$ distance may not be required on coordination with the thiocarbonyl group. A M.O. calculation of the compound $\mathrm{Cu}(3-\mathrm{MeRd}) \mathrm{I}$ is in progress.

\section{(b) Complexes of 3-substituted rhodanines}

The complexes of these ligands are derived from $\mathrm{Cu}(\mathrm{I}), \mathrm{Pd}(\mathrm{II})$ or $\mathrm{Pt}(\mathrm{II})$ and from the undissociated ligands. The important features of the i.r. spectra of these products as compared to those of the ligands are: (1) a lowering in frequency or a weakening intensity of the absorption bands assigned to $\nu \mathrm{C}=\mathrm{S}$, (2) one or more new bands in the $300-400 \mathrm{~cm}^{-1}$ region which may be assigned to $\mathrm{M}-\mathrm{S}$ stretching vibrations. These have been interpreted as coordination of the ligands through the the thiocarbonyl group. A weakening or complete disappearance of the $\mathrm{C}=\mathrm{S}$ stretching vibration was observed on coordination through sulphur in the case of 2-thiourea and 1-methyl-2-thiourea [10,11]. NMR data shown in Table 2 indicate no significant shifts of absorptions suggesting that the ligand has not been changed during complexation.

Olefenic tertiary phosphines and arsines containing the allyl group form chelates with $\mathrm{Cu}(\mathrm{I}), \mathrm{Pd}(\mathrm{II})$ or $\mathrm{Pt}(\mathrm{II})$ in which both the group $V$ atom and the double bond are coordinated to the metal[12,13]. The but-3-enylphosphine chelates with the double bond to palladium or platinum [14]. In the ligand 3-allylrhodanine it is possible that the metal has also been coordinated with the allyl group. The i.r. spectra of the complexes $M(\mathrm{AllRd})_{2} \mathrm{Cl}_{2}$ with $M=\mathrm{Pd}$ or $\mathrm{Pt}$ show a band at about $1640 \mathrm{~cm}^{-1}$ due to an uncoordinated $C=C$ stretching vibration [15]. It seems

9. R. G. Vranka and E. L. Amma, J. Am. chem. Soc. 88, 4270 (1966).

10. A. Yamaguchi, R. B. Penland, S. Mizushima, J. T. Lane, C. Curran and J. V. Quagliano, J. Am. chem. Soc. 79, 1575 (1957).

11. T. J. Lane, A. Yamaguchi, J. V. Quagliano, J. A. Ryan and S. Mizushima, J. Am. chem. Soc. 81 3824 (1959).

12. M. A. Bennett, W. R. Kneen and R. S. Nyholm, Inorg. Chem. 7, 552 (1968).

13. M. A. Bennett, W. R. Kneen and R. S. Nyholm, Inorg. Chem. 7, 556 (1968).

14. R. N. Haszeldine, R. J. Lunt and R. V. Parish, J. chem. Soc. (A) 3705 (1971).

15. F. R. Hartley, Chem. Rev. 799 (1969). 
likely that only the sulphur atom of the ligand is attached to the metal in these complexes. However the complex $\mathrm{Cu}(\mathrm{AllR}$ d) $\mathrm{Cl}$ shows no band at about 1640 $\mathrm{cm}^{-1}$, but a band at $1538 \mathrm{~cm}^{-1}$, suggesting coordination with the olefinic double bond. The shift of the $\mathrm{C}=\mathrm{C}$ frequency $\left(100 \mathrm{~cm}^{-1}\right)$ on coordination is of the same order as that observed in copper(I) complexes of 3-allylpyridine and $o$-allylphenyldiphenylphosphine $[12,16]$.

The NMR spectra of the complexes are similar to that of the free ligand, suggesting that these data give no additional criterion for coordination of the olefenic double bond in the complexes. The fact that there is no shift of the allyl protons in the copper(I) complex may be due to dissociation of this compound in DMSO solution. In agreement with this result we found in the i.r. spectrum in DMSO solution the $\mathrm{C}=\mathrm{C}$ frequency at $1640 \mathrm{~cm}^{-1}$.

The ligands 3,3'-ethylenebisrhodanine and 3,3'-butylenebisrhodanine contain 2 thiocarbonyl groups. The palladium complexes with these ligands have the formula $\mathrm{Pd}\left(\right.$ ligand) $\mathrm{Cl}_{2}$. The structure of these complexes may be described as a monomeric complex containing a bidentate ligand (Structure I) or as a dimeric complex with the chloride atom as bridge (Structure II) or it may be even a polymeric structure (Structure III):<smiles></smiles>

(I)<smiles></smiles>

(II)<smiles>C[Te]C[Te](Cl)(Cl)C[Te]C[Te](Cl)(Cl)[Te]CC[R](C)(C)C</smiles>

(III)

These palladium compounds are only slightly soluble in the usual organic solvents and it was not possible to obtain mol. wt measurements to distinguish between a monomeric, dimeric and a polymeric structure.

Acknowledgements - The authors wish to thank Prof. Dr. Ir. J. J. Steggerda for his continous interest in this work and Mr. J. Diersman for performing the analyses.

16. R. E. Yingst and R. E. Douglas, Inorg. Chem. 3, 1177 (1964). 